\title{
Real-time setup to measure radon emission during rock deformation: implications for geochemical surveillance
}

\author{
P. Tuccimei ${ }^{1}$, S. Mollo ${ }^{2}$, M. Soligo ${ }^{1}$, P. Scarlato ${ }^{2}$, and M. Castelluccio ${ }^{1}$ \\ ${ }^{1}$ Università "Roma Tre”, Dipartimento di Scienze, Largo S. L. Murialdo 1, 00146 Roma, Italy \\ ${ }^{2}$ Istituto Nazionale di Geofisica e Vulcanologia, Via di Vigna Murata 60, 00143 Roma, Italy \\ Correspondence to: P. Tuccimei (paola.tuccimei@uniroma3.it)
}

Received: 24 November 2014 - Published in Geosci. Instrum. Method. Data Syst. Discuss.: 4 February 2015

Revised: 27 April 2015 - Accepted: 11 May 2015 - Published: 27 May 2015

\begin{abstract}
Laboratory experiments can represent a valid approach to unravel the complex interplay between the geochemical behaviour of radon and rock deformation mechanisms. In light of this, we present a new real-time experimental setup for analysing in continuum the alpha-emitting ${ }^{222} \mathrm{Rn}$ and ${ }^{220} \mathrm{Rn}$ daughters over variable stress-strain regimes. The most innovative segment of this setup consists of the radon accumulation chamber obtained from a tough and durable material that can host large cylindrical rock samples. The accumulation chamber is connected, in a closed-loop configuration, to a gas-drying unit and to a RAD7 radon monitor. A recirculating pump moves the gas from the rock sample to a solid-state detector for alpha counting of radon and thoron progeny. The measured radon signal is enhanced by surrounding the accumulation chamber with a digitally controlled heating belt. As the temperature is increased, the number of effective collisions of radon atoms increases favouring the diffusion of radon through the material and reducing the analytical uncertainty. The accumulation chamber containing the sample is then placed into a uniaxial testing apparatus where the axial deformation is measured throughout a linear variable displacement transducer. A dedicated software allows obtaining a variety of stress-strain regimes from fast deformation rates to long-term creep tests. Experiments conducted with this new real-time setup have important ramifications for the interpretation of geochemical anomalies recorded prior to volcanic eruptions or earthquakes.
\end{abstract}

\section{Introduction}

Positive radon anomalies in soil gas and groundwater are commonly observed prior to earthquake ruptures and volcanic eruptions, attracting considerable attention in studies on precursory geochemical signals (Cox et al., 1980; King et al., 1995; Linde and Sacks, 1998; Roeloffs, 1999; Trique et al., 1999). However, this simplified picture is frequently contradicted by the lack of significant anomalies recorded before an earthquake (Kerr, 1978; King, 1981; Tsunogai and Wakita, 1995; Steinitz et al., 2003). Moreover, negative anomalies are sometimes measured at the seismic source (Hauksson, 1981; Kuo et al., 2006), while contemporaneous positive anomalies are inexplicably recorded at monitoring stations located hundreds of kilometres away (Kerr, 1978, 1981). Alternating increases and decreases of radon emissions are also measured prior to earthquakes (Wakita et al., 1980; Igarashi et al., 1995).

Hence, although the radon signal is routinely measured and monitored in the field as possible precursor of earthquakes and volcanic eruptions, in many cases the simple monitoring of radon emission does not appear to be useful as a warning signal. In view of this, laboratory experiments may represent the key to better understand the complex relationship between the geochemical behaviour of radon and rock deformation mechanisms. Paradoxically, a few experimental studies in the history of Earth sciences have attempted to understand the relationships between radon emission rate and rock deformation. In their early and pioneer work, Holub and Brady (1981) performed uniaxial compression tests on granite samples to monitor changes in radon exhalation as a function of microfracturing. Tests were carried out by cycli- 
cally loading and unloading samples to increase rock damage. However, from an analytical point of view, radon measurement cycles lasting up to 200 min made difficult to understand the relationship between radon exhalation and microcrack growth. Moreover, radon emissions were measured using an alpha radiation detection scintillator that did not discriminate radon isotopes and was also affected by a large analytical uncertainty. Using a more accurate radon measurement system, Tuccimei et al. (2010) and Mollo et al. (2011a) presented a new data set on radon emission from different rock samples uniaxially deformed over incremental loading conditions. The analytical system allowed for the simultaneous measurement of both radon main isotopes, i.e. radon $\left({ }^{222} \mathrm{Rn}\right)$ and thoron $\left({ }^{220} \mathrm{Rn}\right)$, using the ${ }^{218}$ Po peak for ${ }^{222} \mathrm{Rn}$ and ${ }^{216} \mathrm{Po}$ peak for ${ }^{220} \mathrm{Rn}$. Using this counting system, a rapid equilibrium between polonium and radon nuclei is achieved; therefore, the radon signal responds quickly (in the order of a few minutes) to any change in rock deformation, also reducing significantly the analytical uncertainty (Tuccimei et al., 2006, 2011). Results from experiments of Tuccimei et al. (2010) have evidenced that negative radon anomalies measured in soil gas and groundwater may be explained by the deformation of loosely consolidated and/or highly porous rocks due to a pore collapse process that reduces the radon exhaling surface. In contrast, Mollo et al. (2011a) have demonstrated that no significant radon changes are recorded prior to an earthquake due to the deformation of low porosity and high strength crystalline igneous rocks. Only after failure, when a macroscopic rupture surface develops (e.g. in the form of an earthquake), a significant increase in radon emission is recorded. This also suggests that geological bedrock consisting of high-strength materials could drastically reduce the prediction potential of radon monitoring in active seismic and volcanic areas.

The experiments described above have important ramifications for the use of radon emissions as a predictive tool. Namely, they go some way in providing an explanation for the seemingly confusing array of radon anomalies seen prior to earthquakes in nature. However, the measured radon signal is the result of a stepped experimental strategy in which the sample is firstly deformed in a uniaxial machine and then its radon emission is analysed in a counting system. We term this laboratory strategy as "snapshot experiments" because they can only provide radon emissions from a rock sample deformed at predetermined stress conditions. Thus, interpretations about changes of radon emission through time rest on the assumption that a rock sample deformed at the same stress value produces an identical radon emission irrespective of load paths and stress trajectories. Obviously, snapshot experiments do not simulate the natural variability of stressstrain conditions and, consequently, the evolution of radon signals during continuous rock deformation is still under debate.

Due to the lack of appropriate methodologies to reproduce radon anomalies in the laboratory, here we present the result

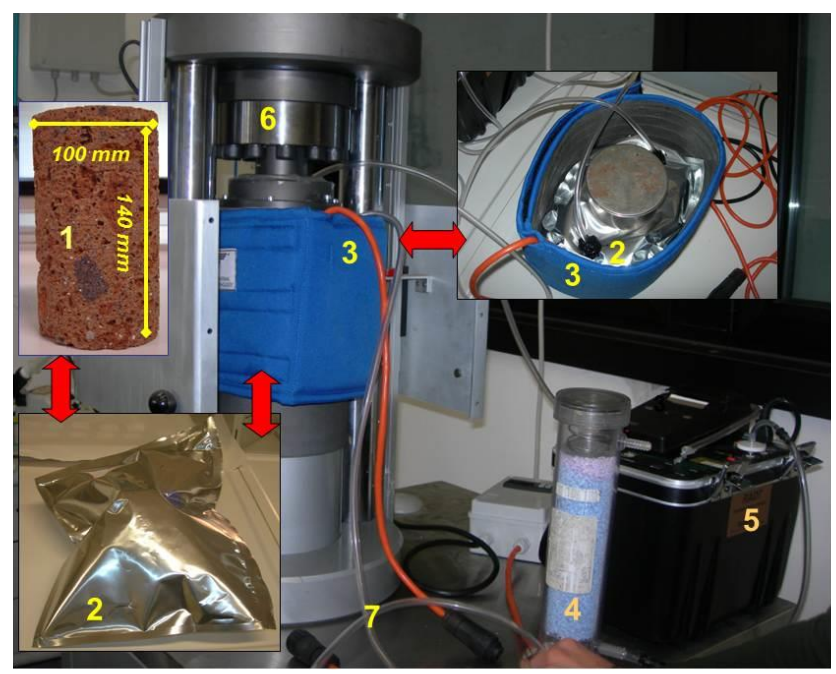

Figure 1. Experimental setup for the detection of ${ }^{222} \mathrm{Rn}$ and ${ }^{220} \mathrm{Rn}$ activity concentrations from rocks under uniaxial deformation. The system consists of: rock sample (1), DryPack accumulation chamber (2), digitally controlled heating belt (3), desiccant (4), RAD 7 radon monitor (5), uniaxial press (6), and vinyl tubing (7). Arrows connect the different sections of the experimental system to give a complete view of it. See text for explanation.

of the efforts conducted to develop and test a real-time experimental setup for measuring radon emissions during rock deformation. This system allows us to fully unravel the complex relationship between rock deformation style and radon emission rate by analysing in continuum the alpha-emitting ${ }^{222} \mathrm{Rn}$ and ${ }^{220} \mathrm{Rn}$ daughters.

\section{Overview of the real-time experimental setup}

\subsection{Radon counting system}

The most innovative segment of the experimental setup described in this study is the radon accumulation chamber obtained from a "dry pack" material (DryPack ${ }^{\mathrm{TM}}$ 3750, ITW Richmond Technology) made up of three extremely tough and durable layers: (i) an external polyester film, (ii) an intermediate solid aluminium shielding foil, and (iii) an internal antistatic polyethylene interior sealant. The dry pack is cut and modelled to obtain a chamber of $36 \times 30 \times 15 \mathrm{~cm}$ (Fig. 1). The rock sample is inserted into the chamber and then each side of the dry pack is thermosealed. Two holes are drilled at opposite sides of the dry pack to insert $140 \mathrm{~cm}$ long vinyl tubes that connect, in a closed-loop configuration (Fig. 1), the accumulation chamber to a gas-drying unit filled with a desiccant $\left(\mathrm{CaSO}_{4}\right.$ with $3 \% \mathrm{CoCl}_{2}$, as indicator) and to a RAD7 radon monitor (Durridge Company Inc.). All the connecting junctions are then carefully sealed with silicon to avoid radon leakage. 
To enhance the radon signal and reduce the analytical uncertainty, the accumulation chamber containing the rock sample is kept at a constant temperature through a customdesigned, digitally controlled heating belt surrounding the chamber (Fig. 1). The belt consists of a heating textile with a warp-knitted basis structure (68\% PES and $32 \%$ carbon fibre) operating up to $90^{\circ} \mathrm{C}$. The temperature is monitored by an insulated Pt100 resistance thermometer with accuracy $\pm 1{ }^{\circ} \mathrm{C}$ (factory calibrated in oil bath and air by SAB Bröckskes) that is connected to a $1 / 16$ in. DIN size controller (OMRON E5CSV). This specific device is intended to exploit the higher mobility of the gas supplying thermal energy to the radon atoms. As the temperature is increased, the number of effective collision of radon atoms with other molecules and grain walls is enhanced favouring the diffusion of radon through the smallest pores of the material. The end result is a higher radon exhalation with lower uncertainty that strongly improves the ability of the system to capture any departure from radioactive equilibrium (Tuccimei et al., 2009, 2011).

A recirculating pump in the RAD7 moves the gas from the accumulation chamber through both the desiccant and inlet filter to a solid-state detector for alpha counting of radon and thoron progeny. The electrostatic detector collects the charged ions and discriminates the electrical pulses generated by their alpha particles. This allows selecting only the short-lived ${ }^{218} \mathrm{Po}$ and ${ }^{216} \mathrm{Po}$ counting for a rapid determination of ${ }^{222} \mathrm{Rn}$ and ${ }^{220} \mathrm{Rn}$, respectively. The radioactive equilibrium between ${ }^{218} \mathrm{Po}$ and ${ }^{222} \mathrm{Rn}$ is achieved in about $15 \mathrm{~min}$, i.e. about 5 times the half-life of ${ }^{218} \mathrm{Po}$, whereas the equilibrium between ${ }^{216} \mathrm{Po}$ and ${ }^{220} \mathrm{Rn}$ occurs in a few seconds only, as the result of the very short thoron half-life of $55.6 \mathrm{~s}$.

The accumulation chamber containing the sample and surrounded by the heating belt is then placed into a uniaxial testing apparatus (Fig. 1) with a maximum loading capacity of $250 \mathrm{kN}$ (cf. Mollo et al., 2011b). The axial deformation is measured throughout a linear variable displacement transducer (LVDT, extensimeter) with a resolution of $1 \mu \mathrm{m}$. A dedicated software allows switching from deformation to load control and viceversa at any time of the experiment. Since the piston is controlled via microadjustments operated by a servo-controller actuator, the machine is suitable for a wide variety of stress-strain experiments from fast deformation rates to long-term creep tests.

\subsection{Testing material}

The material used to test the experimental setup is the socalled "Tufo Rosso a Scorie Nere" (hereafter named TRSN). This is a lithophysae-rich tuff sampled from a pyroclastic flow of the Vico volcanic apparatus (Latium, Italy). The tuff belongs to the main body of a reddish ignimbrite deposit, containing sanidine crystals and black pumices, mostly centimetric in size. We have chosen TRSN because the relationship between radon emission and tuff deformation of

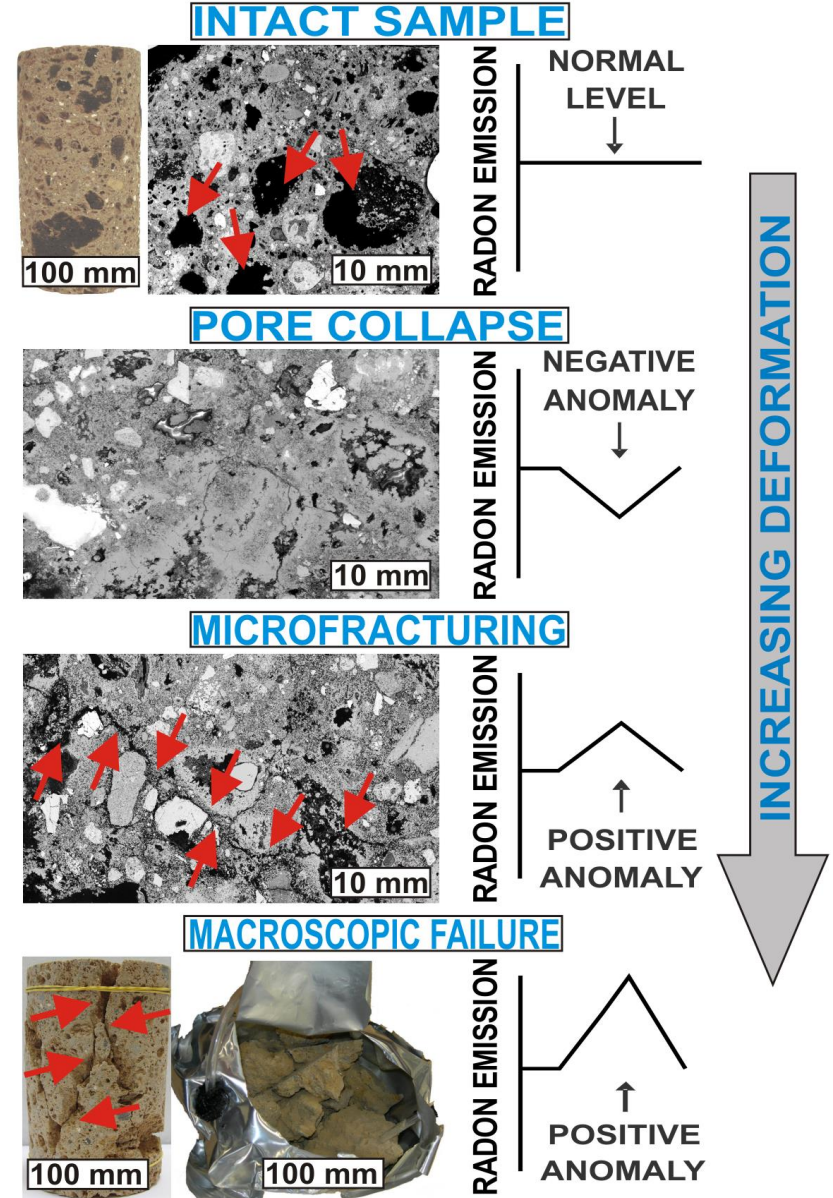

Figure 2. Schematic overview of the relationship between TRSN sample deformation and radon emission as determined by previous studies (Hudyma et al., 2004; Tuccimei et al., 2006, 2009, 2011). Back-scattered electron (BSE) images were obtained using a fieldemission scanning electron microscopy (FE-SEM) at the HP-HT Laboratory of Experimental Volcanology and Geophysics of the Istituto Nazionale di Geofisica e Vulcanologia in Rome (Italy). Large cavities, vugs and vesicles (i.e. lithophysae) are indicated for the intact sample. Due to pore collapse, no lithophysae are observable for the densely compacted sample; consequently, radon emission decreases. In contrast, microfractures are formed prior to rock failure, causing a positive geochemical anomaly. After rupture, the formation of macroscopic exhaling surface further increases the radon emission.

this material has been the focus of previous studies (Tuccimei et al., 2010; Mollo et al., 2011a; Scarlato et al., 2013). As reported by Tuccimei et al. (2010), TRSN has a total porosity of about $47 \%$ with a characteristic bimodal distribution (Fig. 2): macroporosity (from $1 \mathrm{~mm}$ to $1 \mathrm{~cm}$ ) and microporosity (from 1 to $100 \mu \mathrm{m}$ ). Generally, this high porosity is due to larger cavities, vugs and vesicles that overprint smaller discontinuities, such as grain boundaries, cracks and flaws. The bimodal porosity is typical in volcanic environments where macroporosity is given from lithophysae, 
i.e. centimetre-scale cavities formed by trapped pockets of gas within the cooling volcanic ash. Generally, larger cavities are the main source of porosity and their variability in size and shape were seen to control the radon exhalation (Tuccimei et al., 2006) and mechanical properties of lithophysal tuff (Hudyma et al., 2004). Due to the presence of a high number of pores, TRSN is extremely weak with an uniaxial compressive strength (UCS; i.e. the capacity of a material to withstand axially directed pushing forces prior to failure) $<2.4 \mathrm{MPa}$. Thus, as the load is increased, the deformation proceeds via two main mechanisms (Fig. 2): pore collapse and microfracturing. The extensive pore collapse is due to the closure of both macropores and micropores (Fig. 2), i.e. the porosity decreases from 47 to $40 \%$ (Tuccimei et al., 2010), causing a densification of the material, i.e. both P-wave velocity (Scarlato et al., 2013) and bulk density increase from $1.3 \mathrm{~km} \mathrm{~s}^{-1}$ and $0.9 \mathrm{~g} \mathrm{~cm}^{-3}$ to $1.8 \mathrm{~km} \mathrm{~s}^{-1}$ and $1.3 \mathrm{~g} \mathrm{~cm}^{-3}$, respectively. According to Tuccimei et al. (2010), with respect to the normal level of radon emission recorded for the intact TRSN sample, a negative geochemical anomaly is measured due to the reduction of porosity (Fig. 2), i.e. as the exhaling surface is reduced. On the other hand, prior to TRSN sample rupture, microfractures develop gradually into macrofractures (Fig. 2); indeed, microfracturing has been recognized by early studies (e.g. Brace et al., 1966; Scholz, 1968; Wawersik, 1972) to be the main mechanism responsible for the formation of macroscopic failure. Consequently, the radon emission progressively increases (Fig. 2) giving reason for the high positive anomaly recorded as macroscopic exhaling surfaces are progressively produced by deformation (Tuccimei et al., 2010)

TRSN is characterized by a high radium activity concentration $\left({ }^{226} \mathrm{Ra}=254 \mathrm{~Bq} \mathrm{~kg}^{-1}\right)$ and high uranium $(21.2 \mathrm{ppm})$ and thorium (52.3 ppm) contents (Tuccimei et al., 2006). The significant concentration of these nuclides, which are precursors of radon isotopes, along with the presence of macroporosity, made this material particularly suitable to analyse variations of radon and thoron emissions under variable loads. Moreover, to obtain a strong geochemical signal, we used large cylindrical samples of $100 \mathrm{~mm}$ in diameter and $140 \mathrm{~mm}$ in length. The intact rock samples oven-dried at $110^{\circ} \mathrm{C}$ for $24 \mathrm{~h}$ are characterized, at room temperature, by an initial average ${ }^{222} \mathrm{Rn}$ and ${ }^{220} \mathrm{Rn}$ exhalation rates of 7.9 and $314 \mathrm{~Bq} \mathrm{~kg}^{-1} \mathrm{~h}^{-1}$, respectively (Tuccimei et al., 2010).

\subsection{Experimental protocol}

A dried TRSN sample is loaded into the accumulation chamber that is then thermosealed. Although a constant activity concentration of ${ }^{220} \mathrm{Rn}$ is achieved in a few minutes, a period of at least 20 days is required to reach ${ }^{222} \mathrm{Rn}$ radioactive equilibrium. Such a feature puts forward the preferential use in laboratory experiments of ${ }^{220} \mathrm{Rn}$ for monitoring rapid changes of radon emission during rock deformation (cf. Tuccimei et al., 2010; Mollo et al., 2011a). Indeed, thoron re- sponds almost instantaneously to rock deformation changes, drastically reducing the length of a single measurement cycle. Moreover, even if ${ }^{222} \mathrm{Rn}$ rather than ${ }^{220} \mathrm{Rn}$ is usually monitored in volcanic and seismic areas due to its higher activity concentration and longer half-life, results from laboratory analyses based on ${ }^{220} \mathrm{Rn}$ are certainly comparable with natural processes releasing ${ }^{222} \mathrm{Rn}$ since heavy radon and thoron isotopes do not fractionate due to their low mass difference $(0.01 \%)$.

At the end of the equilibration period, the accumulation chamber is connected to the RAD 7, and the heating belt is set to the desired experimental temperature. A few hours are needed to reach stable initial conditions in the experimental setup, e.g. temperature homogenization in the closed-loop configuration. A period of $30 \mathrm{~min}$ is selected as acquisition time of a single measurement cycle. To reduce the uncertainty associated with eventual slight variations of temperature and load, 48 cycles per day (with $30 \mathrm{~min}$ acquisition time) are collected. For each data set the uncertainty of the mean at $95 \%$ confidence level is then calculated. The initial $24 \mathrm{~h}$ average ${ }^{220} \mathrm{Rn}$ activity concentration is generally chosen as reference value to highlight any change in thoron concentration under variable load conditions. The influence of other parameters on radon emission, such as air relative humidity and detection temperature in the closed-loop configuration, were the object of previous studies (Tuccimei et al., 2006, 2009, 2011), demonstrating also that no gas sorption phenomena occur on the desiccant (i.e. on the $\mathrm{CaSO}_{4}$ grains).

It is worth stressing that radon is chemically inert and its transport behaviour in rocks is dominated by migration through connected pores and cracks (either pre-existing or stress-induced). Its short recoil length $\left(3 \times 10^{-8} \mathrm{~cm}\right)$, due to a short lifetime diffusion distance, implies that only atoms produced at the surface of grains, trapped within the space of pores and/or adsorbed by the free inner surface of microcracks can be released from rock to the surrounding medium. Thus, the behaviour of radon emission from rocks subjected to variable stress conditions is primarily dependent on the increase or decrease of the rock exhaling surface (e.g. Sengupta et al., 2005; Banerjee et al., 2011). This means that, using our closed-loop experimental setup, changes in radon emission result in a new value of equilibrium activity concentration within the inner volume of the equipment, namely (i) a ${ }^{220} \mathrm{Rn}$ increment if the exhalation surface increases due to microfracturing and failure (Banerjee et al., 2011; Mollo et al., 2011a) and (ii) a ${ }^{220} \mathrm{Rn}$ radon reduction if the exhalation surface decreases due to rock pore collapse and compaction (Sengupta et al., 2005; Tuccimei et al., 2010). 


\section{Results and interpretation}

\subsection{Temperature-dependent radon concentration experiments}

A large number of studies is concerned with the effect of physical parameters on radon fluxes and concentrations through the pores of geological materials. Seasonal fluctuations of temperature are strictly correlated with changes of soil radon abundances. For example, summer climatic conditions make top soil dry, enhancing its permeability (e.g. Wiegand, 2001); at the same time, as the daily or seasonal temperature increases, the diffusion and release of radon at the soil-air interface increases and the gas concentration at shallow depth decreases (e.g. Wiegand, 2001; Iskandar et al., 2004). Similarly, previous laboratory measurements of radon exhalation rates have evidenced the same direct positive correlation between radon emission and sample temperature (Stranden et al., 1984; Tuccimei et al., 2009). Thus, the use of thermal enhancement to increase atomic mobility and therefore radon emission may be crucial in the study of lowemitting, natural materials (e.g. limestones, travertines and siliceous sands) and, importantly, to reduce the uncertainty associated with the analytical measurement (Tuccimei et al., 2006, 2011).

Here we present results from temperature-dependent radon concentration (TDRC) measurements performed to found the thermal conditions leading to the highest radon signal and lowest analytical error. Measurements were carried out using our experimental setup consisting of (i) the dry pack accumulation chamber, (ii) the TRSN sample, (iii) the heating belt, and (iv) the RAD7 radon monitor (Fig. 1). ${ }^{220} \mathrm{Rn}$ activity concentrations were obtained by means of $30 \mathrm{~min}$ counting cycles. Our analyses were initially conducted at room temperature (i.e. $24.3^{\circ} \mathrm{C}$ ); then, the temperature was progressively increased from 30 to $90^{\circ} \mathrm{C}$ using an incremental step of $10^{\circ} \mathrm{C}$ and maintaining the temperature constant for $24 \mathrm{~h}$ during each step. All data recorded during 8 days of measurements are plotted in Fig. 3a and highlight that the thoron signal increases with increasing temperature.

In order to quantify this relationship, we have calculated the average ${ }^{220} \mathrm{Rn}$ activity concentration for each $24 \mathrm{~h}$ measurement. Results are presented in Fig. 3b, attesting a positive exponential dependence of thoron signal from temperature. The regression analysis based on data exponential fitting yields a good correlation coefficient $(R=0.995)$ with a high confidence interval for the eight data points $\left(\alpha_{0.001}=0.925\right)$. Moreover, as the temperature is increased, the uncertainty of the $24 \mathrm{~h}{ }^{220} \mathrm{Rn}$ mean at $95 \%$ confidence interval decreases from $5 \%$ (at room temperature) to $2.7 \%$ (at $90^{\circ} \mathrm{C}$ ), demonstrating a significant improvement of data resolution. Notably, although the $24 \mathrm{~h}$ thoron activity concentration is increased by $30 \%$ at $90^{\circ} \mathrm{C}$, the $24 \mathrm{~h}$ average temperature measured in the detection chamber of the RAD7 slightly changes from 21.6 to $25.7^{\circ} \mathrm{C}$ (Fig. 3b). This finding is very impor-
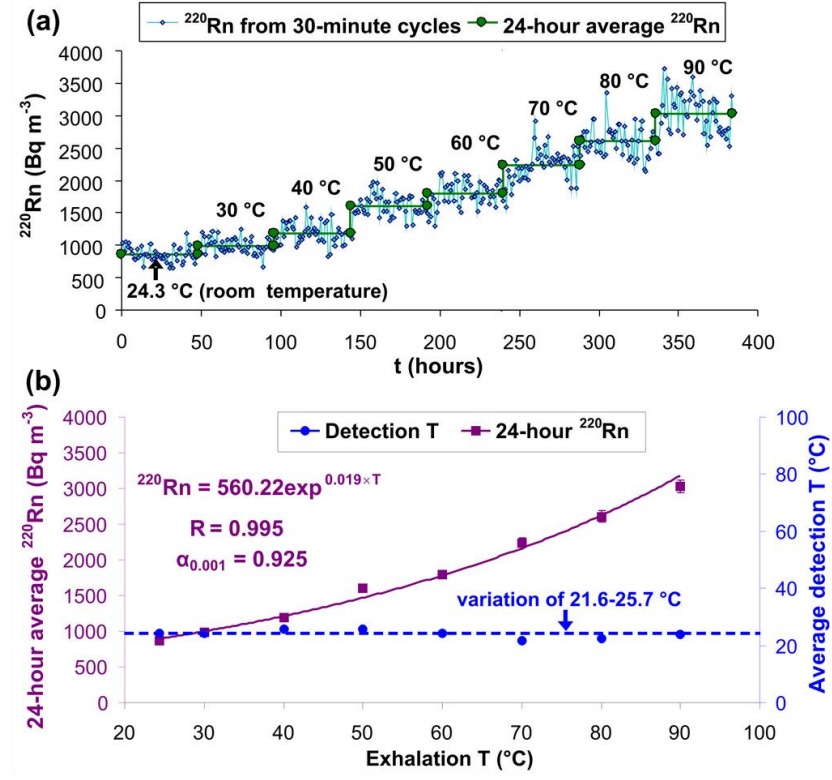

Figure 3. ${ }^{220} \mathrm{Rn}$ (thoron) data from temperature-dependent radon concentration (TDRC) experiments conducted at room temperature and from 30 to $90^{\circ} \mathrm{C}$ (using steps of $10^{\circ} \mathrm{C}$ ). ${ }^{220} \mathrm{Rn}$ data from 30 min cycles are plotted together with $24 \mathrm{~h}$ average ${ }^{220} \mathrm{Rn}$ activity concentrations (a). $24 \mathrm{~h}$ average ${ }^{220} \mathrm{Rn}$ activity concentrations are also plotted versus the exhalation temperature (b). Uncertainties of the mean are calculated at a confidence level of $95 \%$. Regression analysis yields an exponential fitting with a correlation coefficient of $0.925(\alpha)$, which is the 0.001 probability reference value for eight data points. The correlation factor $(R)$ is also very high (0.995). The $24 \mathrm{~h}$ average detection temperature in the radon monitor is plotted versus the exhalation temperature of the TRSN sample (b). No significant changes are observed for the detection temperature, showing a variation lesser than $4{ }^{\circ} \mathrm{C}$.

tant for assessing the overall quality of our measurements. In fact, a great increase of the detection temperature at constant relative humidity would reduce the counting efficiency of the solid-state silicon detector, leading to biased analytical results and misleading interpretations of the data (Roca et al., 2004; Tuccimei et al., 2011).

On the basis of TDRC data, we have conducted deformation experiments at $90^{\circ} \mathrm{C}$ corresponding to the maximum operating temperature of the heating belt and providing the lowest analytical uncertainty. We stress that thermal conditions $>100{ }^{\circ} \mathrm{C}$ are not recommended for our experiments due to the thermal decomposition of volatile-bearing minerals hosted in rocks as primary or secondary crystals, xenocrysts, and matrix cement. For example, the dehydration and dehydroxylation of $\mathrm{H}_{2} \mathrm{O}$-bearing minerals, such as clays and zeolites, start at $100^{\circ} \mathrm{C}$ (Heller-Kallai et al., 1989) and proceed up to $800^{\circ} \mathrm{C}$ (Che et al., 2011); whereas, the decarbonation of $\mathrm{CO}_{2}$-bearing minerals starts at 500 and $700{ }^{\circ} \mathrm{C}$ for dolomite (Rodriguez-Navarro et al., 2012) and calcite (Mollo et al., 2013), respectively. Several studies have ex- 


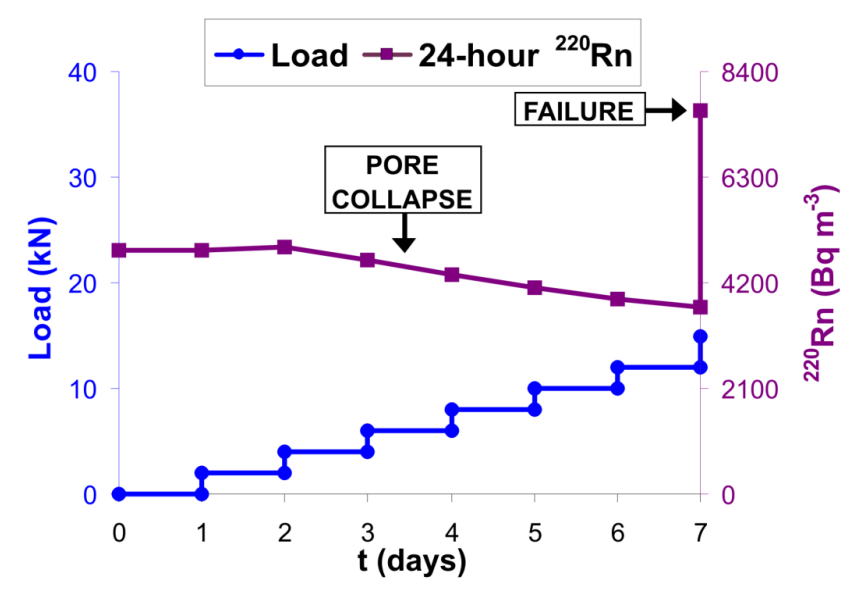

Figure 4. Deformation-dependent radon concentration (DDRC) $\mathrm{R} 1$ experiment, at constant temperatures of $90^{\circ} \mathrm{C}$. The uniaxial load and $24 \mathrm{~h}$ average ${ }^{220} \mathrm{Rn}$ activity concentration are plotted versus the experimental time. Six different load steps of 2, 4, 6, 8, 10, and $12 \mathrm{kN}$ were used and the load was maintained constant for 1 day for each step. ${ }^{220} \mathrm{Rn}$ activity concentration invariably decreases with increasing load due to pore collapse. At $12 \mathrm{kN}$, the load was increased up to sample failure and the thoron signal substantially increased due to the formation of macroscopic exhaling surfaces.

perimentally demonstrated that the thermal decomposition of these minerals results in a progressive change of the physical properties of the geological materials (i.e. porosity, Young's modulus, Poisson's ratio, and P- and S-wave velocities) reducing significantly their strength via thermal microcracking or intercrystalline plasticity (Heap et al., 2012, 2013; Mollo et al., 2012, 2013). Therefore, it is crucial to prevent thermally induced reactions to correctly assess changes in radon emission during deformation of naturally formed rocks.

\subsection{Deformation-dependent radon concentration experiments}

To test the ability of our real-time experimental setup for measuring radon variations during rock deformation, we have designed three different types of DeformationDependent Radon Concentration (DDRC) experiments, i.e. R1, R2 and R3, conducted under variable load-time conditions from 1 to $15 \mathrm{kN}$ and from 7 to 17 days. Each DDRC experiment was also replicated to verify data reproducibility; the whole analytical data set is reported in the Table 1. According to results from TDRC experiments (Fig. 3), each deformation test was carried out at $90^{\circ} \mathrm{C}$ to maximize the thoron signal and reduce the analytical uncertainty; notably, the TRSN sample was also kept at $90^{\circ} \mathrm{C}$ for 1 day to achieve thermal homogenization prior to loading (see, the horizontal segment from 0 to 1 on the $x$ axis (days), with $y$ coordinate $(\mathrm{kN})$ equal to 0 ). The load values and thoron activity concentrations (expressed as $24 \mathrm{~h}{ }^{220} \mathrm{Rn}$ mean activity concentration in the closed-loop setup) measured during experiment $\mathrm{R} 1$ are

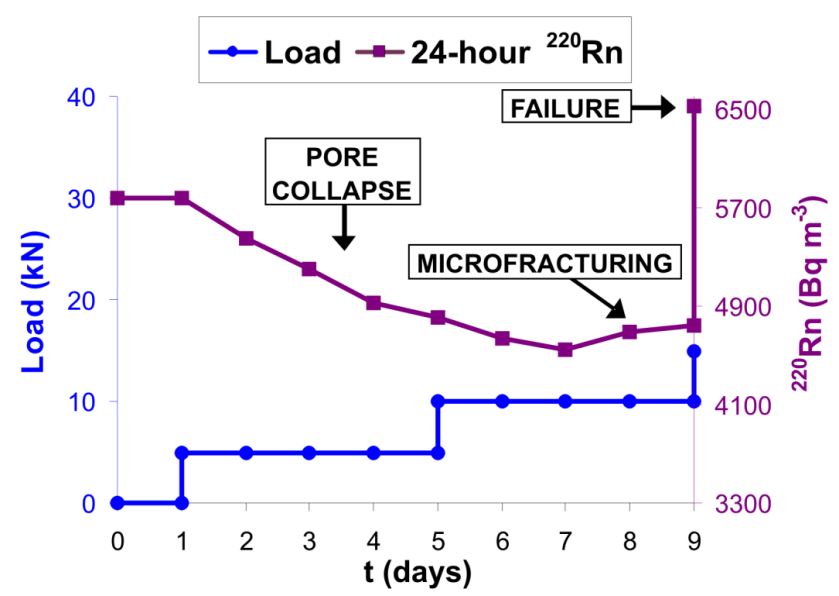

Figure 5. DDRC experiment R2, at constant temperatures of $90^{\circ} \mathrm{C}$. The uniaxial load and $24 \mathrm{~h}$ average ${ }^{220} \mathrm{Rn}$ activity concentration are plotted versus the experimental time. Two load steps from 0 to $5 \mathrm{kN}$ and from 5 to $10 \mathrm{kN}$ were performed. For each step the load was kept constant for 4 days. ${ }^{220} \mathrm{Rn}$ concentration progressively decreases over time accounting for a pore collapse process. However, at $10 \mathrm{kN}$, the thoron signal slightly increases the day before the rupture. This is due to the formation of microfractures, anticipating the macroscopic failure that occurs at about $15 \mathrm{kN}$.

reported in Fig. 4. Six different load steps of 2, 4, 6, 8, 10, and $12 \mathrm{kN}$ were used and the load was maintained constant for 1 day during each step. The load was increased using a rate of $1 \mathrm{kN} \mathrm{min}^{-1}$ to rapidly assure a new thoron equilibrium in the deformed rock. Then, at $12 \mathrm{kN}$ the load was increased up to sample failure (at about $15 \mathrm{kN}$ ). Figure 4 shows that, as the load is higher than $2 \mathrm{kN},{ }^{220} \mathrm{Rn}$ concentration decreases by about $5 \%$ for each step. Only when the TRSN sample is failed, does the thoron signal drastically increase by about $57 \%$. The behaviour of thoron observed from experiment R1 is identical to that measured from snapshot experiments of Tuccimei et al. (2010). As discussed above, the authors demonstrated that thoron emission decreases with increasing load due to a pore closure process that reduces the exhaling surface of TRSN samples (Fig. 2). This finding is also consistent with the knowledge that low porosity rocks exhibit reduced radon flux, in spite of their enhanced radioactive source content (Banerjee et al., 2011). In contrast, at the end of the densification process, microfracturing occurs extensively prior to the formation of a macroscopic fault after failure (Fig. 2), causing an overall increase of ${ }^{220} \mathrm{Rn}$ activity concentration (Fig. 4). As demonstrated by Sengupta et al. (2005), the concentration of radionuclides in a rock is dependent on the microstructural fabric, attesting that microfractures (and, obviously, macroscopic faults) act as pathways for migration of radionuclides.

In Fig. 5 we report the change of thoron signal from experiment R2. Two load steps (i.e. from 0 to $5 \mathrm{kN}$ and from 5 to $10 \mathrm{kN}$, respectively) were performed using a very short 


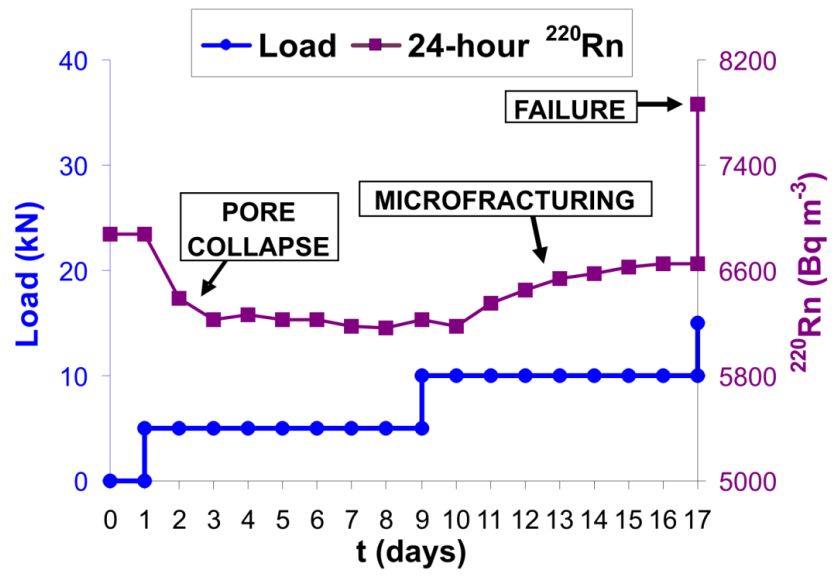

Figure 6. DDRC experiment R3, at constant temperatures of $90^{\circ} \mathrm{C}$. The uniaxial load and $24 \mathrm{~h}$ average ${ }^{220} \mathrm{Rn}$ activity concentration are plotted versus the experimental time. Two load steps from 0 to $5 \mathrm{kN}$ and from 5 to $10 \mathrm{kN}$ were performed. For each step the load was kept constant for 8 days. At $5 \mathrm{kN},{ }^{220} \mathrm{Rn}$ concentration decreases for 3 days. Then, the thoron activity achieved a new equilibrium value due to the attainment of a steady-state deformation condition where pore collapse was counterbalanced by microfracturing. When the load is increased to $10 \mathrm{kN}$, microfracturing prevailed over rock densification and ${ }^{220} \mathrm{Rn}$ concentration progressively increased up to failure.

time to change the load from the first step to the second one (rate of $1 \mathrm{kN} \mathrm{min}^{-1}$ ). During each step the load was kept constant for 4 days (Fig. 5). At the end of the second step, the load was increased to induce sample failure (at about $15 \mathrm{kN}$ ). During the first load step, ${ }^{220} \mathrm{Rn}$ concentration progressively decreases over time by $15 \%$ accounting for the pore collapse process (Fig. 3). Similarly, at the higher loading condition of $10 \mathrm{kN}$, the thoron signal further decreases by $23 \%$ (Fig. 5). However, the day before the sample rupture (i.e. day 8), ${ }^{220} \mathrm{Rn}$ concentration slightly increases (Fig. 5) because of the formation of microfractures that anticipate the macroscopic failure (Fig. 3). After sample rupture, thoron signal drastically increases as the result of (i) the formation of new large exhaling surfaces (Fig. 3), and (ii) the release of gas trapped into the lithophysae of the TRSN sample (Fig. 3).

The R3 experiment was conducted at the same conditions of R2, but the time duration of each loading step was increased from 4 to 8 days (Fig. 6). At $5 \mathrm{kN}$, we observe that ${ }^{220} \mathrm{Rn}$ concentration decreases by $10 \%$ (Fig. 6). At this point (day 3 ), the thoron activity achieves a new equilibrium value and then the signal does not substantially change over time (Fig. 6). Since radon emission decreases due to pore collapse and increases by microfracturing, the almost constant ${ }^{220} \mathrm{Rn}$ concentration suggests the attainment of a steady-state deformation condition (cf. Trippetta et al., 2013, and references therein). Only when the load is increased to $10 \mathrm{kN}$, does microfracturing prevail over rock densification, and the ${ }^{220} \mathrm{Rn}$ concentration progressively increases until sample failure
Table 1. Data set from the DDRC experiments. The $24 \mathrm{~h}$ average ${ }^{220} \mathrm{Rn}$ concentrations and loading conditions are reported for $\mathrm{R} 1$, $\mathrm{R} 2$ and R3 experiments. When the load is increased up to $15 \mathrm{kN}$, all TRSN samples are invariably failed. Each experiment has been replicated three times in order to test the reproducibility of the process at constant temperatures of $90^{\circ} \mathrm{C}$.

\begin{tabular}{|c|c|c|c|}
\hline $\begin{array}{l}\text { Day } \\
\#\end{array}$ & $\begin{array}{r}\text { Load } \\
(\mathrm{kN})\end{array}$ & $\begin{array}{c}24 \mathrm{~h} \\
\text { average } \\
{ }^{220} \mathrm{Rn} \\
\left(\mathrm{Bq} \mathrm{m}^{-3}\right)\end{array}$ & $\begin{array}{l}\text { Uncertainty } \\
\text { at } 95 \% \text { level }\end{array}$ \\
\hline \multicolumn{4}{|c|}{$\mathrm{R} 1$ experiment } \\
\hline & 0 & 4860 & 77 \\
\hline 1 & 2 & 4910 & 72 \\
\hline 2 & 4 & 4650 & 70 \\
\hline 3 & 6 & 4350 & 68 \\
\hline 4 & 8 & 4110 & 65 \\
\hline 5 & 10 & 3890 & 64 \\
\hline 6 & 12 & 3720 & 58 \\
\hline 7 & 15 & 7640 & 92 \\
\hline \multicolumn{4}{|c|}{$\mathrm{R} 2$ experiment } \\
\hline & 0 & 5780 & 104 \\
\hline 1 & 5 & 5450 & 82 \\
\hline 2 & 5 & 5200 & 70 \\
\hline 3 & 5 & 4920 & 76 \\
\hline 4 & 5 & 4810 & 82 \\
\hline 5 & 10 & 4630 & 75 \\
\hline 6 & 10 & 4540 & 73 \\
\hline 7 & 10 & 4690 & 71 \\
\hline 8 & 10 & 4740 & 73 \\
\hline 9 & 15 & 6520 & 122 \\
\hline \multicolumn{4}{|c|}{ R3 experiment } \\
\hline & 0 & 6871 & 84 \\
\hline 1 & 5 & 6386 & 87 \\
\hline 2 & 5 & 6226 & 111 \\
\hline 3 & 5 & 6268 & 97 \\
\hline 4 & 5 & 6220 & 119 \\
\hline 5 & 5 & 6229 & 105 \\
\hline 6 & 5 & 6172 & 116 \\
\hline 7 & 5 & 6162 & 85 \\
\hline 8 & 5 & 6227 & 103 \\
\hline 9 & 10 & 6169 & 108 \\
\hline 10 & 10 & 6353 & 86 \\
\hline 11 & 10 & 6445 & 119 \\
\hline 12 & 10 & 6539 & 119 \\
\hline 13 & 10 & 6580 & 116 \\
\hline 14 & 10 & 6627 & 104 \\
\hline 15 & 10 & 6645 & 101 \\
\hline 16 & 10 & 6655 & 101 \\
\hline 17 & 15 & 7858 & 116 \\
\hline
\end{tabular}


(Fig. 6). As it was observed for experiments R1 and R2, the formation of macroscopic exhaling surfaces (Fig. 3) causes the highest thoron signal due to the fact that radon trapped within the material escapes (Fig. 6).

By comparing data from experiments R1 (Fig. 4), R2 (Fig. 5) and R3 (Fig. 6), we observe that both negative and positive changes of the radon signal may be recorded in the laboratory. This variation could become the key to interpret field monitoring data as geochemical anomalies prior to rupture of the same rock type, in response to the prevailing deformation mechanism. This means that, in seismic or volcanic areas, pore collapse due to low stress conditions may cause significant radon decrease until a constant activity concentration is achieved (Tuccimei et al., 2010). If the low stress condition persists over time (for days and perhaps weeks and months), the radon signal does not change after rock compaction. Conversely, microfracturing due to a high stress condition leads to the formation of new emanation surfaces and substantial increase of the radon signal, although the applied stress remains constant over time. After rock failure, much larger emanation surfaces are created in the form of macroscopic faults and, consequently, most of the radon trapped within the material escapes leading to a significant increase of radon activity concentration in the natural area (Mollo et al., 2011a). Therefore, our real-time experimental setup shows, for the first time, that the imposed stress and time conditions have contrasting repercussions on the radon signal measured by monitoring stations installed for seismic and volcanic surveillance.

\section{Conclusions}

The originality of this study is the development of a new real-time experimental setup to monitor the rapid changes of radon activity concentration during rock deformation. We have therefore designed and tested a new accumulation chamber that allows us to obtain real-time radon measurements during uniaxial deformation experiments. The main advantage of this system is that parameters influencing radon emission other than rock deformation are kept under control. Using a digitally controlled heating belt, the radon signal results to be significant so that it is possible to (i) calculate an average thoron value over a day, (ii) to reduce significantly the uncertainty of the mean, and (iii) to improve the analytical resolution. With respect to previous snapshot experiments from literature, results from our study put emphasis on the great potential of the real-time experimental setup to improve the use of radon gas emissions as predictor for earthquakes and volcanic eruptions.

Acknowledgements. This study was supported by MIUR, PRIN project - Experimental study on radon emission from rocks under mechanical and thermal stress. Implications for volcanic and seismic surveillance - and MIUR, Premiale project - NoRth: New
hORizons of the Technology applied to experimental researches and geophysical and volcanological monitoring. The research activities of the HP-HT laboratory of the INGV were supported by the European Observing System Infrastructure project (EPOS).

Edited by: M. Díaz-Michelena

\section{References}

Banerjee, K. S., Basu, A., Guin, R., and Sengupta, D.: Radon $\left({ }^{222} \mathrm{Rn}\right)$ level variations on a regional scale from the Singhbhum Shear Zone, India: A comparative evaluation between influence of basement U-activity and porosity, Radiat. Phys. Chem., 80, 614-619, 2011.

Brace, W. F., Paulding Jr., B. W., and Scholz, C. H.: Dilatancy in the fracture of crystalline rocks, J. Geophys. Res., 71, 3939-3953, 1966.

Che, C., Glotch, T. D., Bish, D. L., Michalski, J. R., and Xu, W.: Spectroscopic study of the dehydration and/or dehydroxylation of phyllosilicate and zeolite minerals, J. Geophys. Res., 116, E05007, doi:10.1029/2010JE003740, 2011.

Cox, E. M., Cuff, E. K., and Thomas, M. D.: Variations of ground radon concentrations with activity of Kilauea volcano, Hawaii, Nature, 288, 74-76, 1980.

Hauksson, E.: Radon content of groundwater as an earthquake precursor: Evaluation of worldwide data and physical basis, J. Geophys. Res., 86, 9397-9410, 1981.

Heap, M. J., Lavallee, Y., Laumann, A., Hess, K.-U., Meredith, P. G., and Dingwell, D. B.: How tough is tuff in the event of fire?, Geology, 40, 311-314, 2012.

Heap, M. J., Mollo, S., Vinciguerra, S., Lavallée, Y., Hess, K.-U., Dingwell, D. B., Baud, P., and Iezzi G.: Thermal weakening of the carbonate basement under Mt. Etna volcano (Italy): Implications for volcano instability, J. Volcanol. Geoth. Res., 250, 42$60,2013$.

Heller-Kallai, L., Miloslavski, I., and Grayevski, A.: Evolution of hydrogen on dehydroxylation of clay minerals, Amer. Mineral., 74, 818-820, 1989.

Holub, R. F. and Brady, B. T.: The effect of stress on radon emanation from rock, J. Geophys. Res., 86, 1776-1784, 1981.

Hudyma, N., Burcin Avarb, B., and Karakouzian, M.: Compressive strength and failure modes of lithophysae-rich Topopah Spring Tuff specimens and analog models containing cavities, Eng. Geol., 73, 179-190, doi:doi:10.1016/j.enggeo.2004.01.003, 2004.

Igarashi, G., Saeki, S., Takahata, N., Sumikawa, K., Tasaka, S., Sasaki, Y., Takahashi, M., and Sano, Y.: Ground-water radon anomaly before the Kobe earthquake in Japan, Science, 269, 60$61,1995$.

Iskandar, D., Yamazawa, H., and Lida, T.: Quantification of the dependency of radon emanation power on soil temperature, Appl. Radiat. Isot., 60, 971-973, 2004.

Kerr, R. A.: Earthquakes: Prediction proving elusive, Science, 200, 419-421, 1978.

Kerr, R. A.: The mountain is behaving itself - For now, Science, 212, 1258-1259, 1981.

King, C.-Y.: Do radon anomalies predict earthquakes?, Nature, 293, 262, 1981. 
King, C.-Y., Koizumi, N., and Kitagawa, Y.: Hydrogeochemical anomalies and the 1995 Kobe earthquake, Science, 269, 38-39, 1995.

Kuo, T., Fan, K., Kuochen, H., Han, Y., Chu, H., and Lee, Y.: Anomalous decrease in groundwater radon before the Taiwan M 6.8 Chengkung earthquake, J. Environ. Radioact., 88, 101106, 2006.

Linde, A. T. and Sacks, I. S.: Triggering of volcanic eruptions, Nature, 395, 888-890, 1998.

Mollo, S., Tuccimei, P., Heap, M. J., Vinciguerra, S., Soligo, M., Castelluccio, M., Scarlato, P., and Dingwell, D. B.: Increase in radon emission due to rock failure: An experimental study, Geophys. Res. Lett., 38, L14304, doi:10.1029/2011GL047962, 2011a.

Mollo, S., Vinciguerra, S., Iezzi, G., Iarocci, A., Scarlato, P., Heap, M. J., and Dingwell, D. B.: Volcanic edifice weakening via devolatilization reactions, Geophys. J. Int., 186, 1073-1077, 2011 b.

Mollo, S., Heap, M. J., Iezzi, G., Hess, K.-U., Scarlato, P., and Dingwell D. B.: Volcanic edifice weakening via decarbonation: a self-limiting process?, Geophys. Res. Lett., 39, L15307, doi:10.1029/2012GL052613, 2012.

Mollo, S., Heap, M. J., Dingwell, D. B., Hess, K.-U., Iezzi, G., Masotta, M., Scarlato, P., and Vinciguerra, S.: Decarbonation and thermal microcracking under magmatic $P-T-f \mathrm{CO}_{2}$ conditions: the role of skarn substrata in promoting volcanic instability, Geophys. J. Int., 195, 369-380, 2013.

Roca, V., De Felice, P., Esposito, A. M., Pugliese, M., Sabarrese, C., and Vaupotich, J.: The influence of environmental parameters in electrostatic cell radon monitor response, Appl. Radiat. Isotopes, 61, 243-247, doi:10.1016/j.apradiso.2004.03.053, 2004.

Rodriguez-Navarro, C., Kudlacz, K., and Ruiz-Agudo, E.: The mechanism of thermal decomposition of dolomite: New insights from 2D-XRD and TEM analyses, Amer. Min., 97, 38-51, 2012.

Roeloffs, E.: Earth science: Radon and rock deformation, Nature, 399, 104-105, 1999.

Sengupta, D., Ghosh, A., and Mamtani, M. A.: Radioactivity studies along fracture zones in areas around Galudih, East Singhbhum, Jharkhand, India, Appl. Radiat. Isot., 63, 409-414, 2005.

Scarlato, P., Tuccimei, P., Mollo, S., Soligo, M., and Castelluccio, M.: Contrasting radon background levels in volcanic settings: Clues from ${ }^{220} \mathrm{Rn}$ activity concentrations measured during long-term deformation experiments, Bull. Volcanol., 75, 751, doi:10.1007/s00445-013-0751-0, 2013.

Scholz, C. H.: Mechanism of creep in brittle rock, J. Geophys. Res., 73, 3295-3302, 1968.

Steinitz, G., Begin, Z. B., and Gazit-Yaari, N.: Statistically significant relation between radon flux and weak earthquakes in the Dead Sea rift valley, Geology, 31, 505-508, 2003.
Stranden, E., Kolstad, A. K., and Lind, B.: Radon exhalation: moisture and temperature dependence, Health Phys., 47, 480-484, 1984.

Trippetta, F., Collettini, C., Meredith, P. G., and Vinciguerra, S.: Evolution of the elastic moduli of seismogenic Triassic Evaporites subjected to cyclic stressing, Tectonophys, 592, 67-79, 2013.

Trique, M., Richon, P., Perrier, F., Avouac, J. P., and Sabroux, J. C.: Radon emanation and electric potential variations associated with transient deformation near reservoir lakes, Nature, 399, 137-141, 1999.

Tsunogai, U. and Wakita, H.: Precursory chemical changes in ground water: Kobe earthquake, Japan, Science, 269, 61-63, 1995.

Tuccimei, P., Moroni, M., and Norcia, D.: Simultaneous determination of ${ }^{222} \mathrm{Rn}$ and ${ }^{220} \mathrm{Rn}$ exhalation rates from building materials used in Central Italy with accumulation chambers and a continuous solid state alpha detector: Influence of particle size, humidity and precursors concentration, Appl. Radiat. Isotopes, 64, 254-263, 2006.

Tuccimei, P., Castelluccio, M., Soligo, M., and Moroni: M., Radon exhalation rates of building materials: Experimental, Analytical protocol and classification criteria, in: Building Materials: Properties, Performance and Applications, edited by: Cornejo, D. N. and Haro, J. L., Nova Sci., Hauppauge, NY, 259-273, 2009.

Tuccimei, P., Mollo, S., Vinciguerra, S., Castelluccio, M., and Soligo, M.: Radon and thoron emission from lithophysae-rich tuff under increasing deformation: An experimental study, Geophys. Res. Lett., 37, L05305, doi:10.1029/2009GL042134, 2010.

Tuccimei, P., Castelluccio, M., Moretti, S., Mollo, S., Vinciguerra, S., and Scarlato, P.: Thermal enhancement of radon emission from geological materials. Implications for laboratory experiments on rocks under increasing deformation, in: Horizons in Earth Science Research, vol. 4, edited by: Veress, B. and Szigethy, J., Nova Sci., Hauppauge, NY, 247-256, 2011.

Wakita, H., Nakamura, Y., Notsu, K., Noguchi, M., and Asada, T. Radon anomaly: A possible precursor of the 1978 Izu-OshimaKinkai earthquake, Science, 207, 882-883, 1980.

Wawersik, W. R.: Time-dependent rock behavior in uniaxial compression, in: Proceedings of 14th Symp. Rock Mech., Penn. State Univ., University Park, Pa, USA, 85-106, 1972.

Wiegand, J.: A guideline for the evaluation of the soil radon potential based on geogenic and anthropogenic parameters, Environ. Geol., 40, 949-963, 2001. 